\title{
Entrevistas fenomenológicas con egresados de una Institución psiquiátrica: Relatos de experiencias ${ }^{\star}$
}

\section{Phenomenological interviews with graduates from Psychiatric Institution: stories of experiences ${ }^{\star}$}

\section{Entrevista fenomenológica com egressos de Instituição Psiquiátrica: Relatos de experiências*}

\author{
Taiane Soares Vieira ${ }^{1}$; Claudete Ferreira de Souza Monteiro ${ }^{2}$
}

\begin{abstract}
${ }^{1}$ Enfermeira graduada pela Universidade Federal do Piauí - UFPI. Mestranda do Programa de pós-graduação Mestrado em enfermagem da UFPI. Membro do Grupo de Estudos sobre Enfermagem, Violência e Saúde Mental da UFPI. Teresina, PI. Endereço: Rua Bom Jesus 2636, Memorare, CEP: 64009 - 230, email: supertai18@hotmail.com

${ }^{2}$ Doutora em Enfermagem pela Universidade Federal do Rio de Janeiro . Professora adjunto da Universidade Federal do Piauí da Graduação e do Programa de Mestrado em Enfermagem. Coordenadora do Grupo de Estudos sobre Enfermagem, Violência e Saúde Mental da UFPI. Teresina, PI.
\end{abstract}

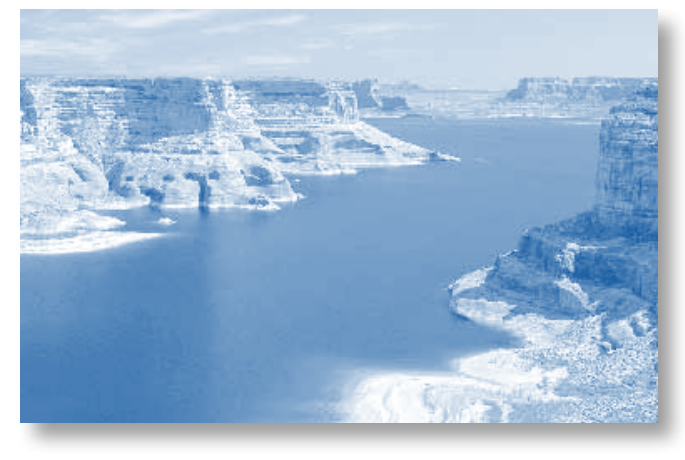

\section{ABSTRACT}

This article aims to describe my experience in aapplying the method of Heideggerian research, in particular the phenomenological interviews with people with mental illness discharged from psychiatric institutions that are currently residents of Therapeutic Residential Services (SRTS). We interviewed nine residents of SRTs in Piauí. In this step several times to walk were striking as the strategy of rapprochement with the interviewees, the location of interviews and even stirring account of the subjects. This experience enabled me to identify what is necessary and important to establish empathy with the subjects, there is no formula for conducting the interview, but it is the researcher to identify the best strategy for obtaining the reports. So is that the empathetic experienced by me in getting the reports of respondents in essence residents through phenomenological interview was crucial to uncovering the meaning of the subjects lived in the daily life of these devices.

Key words: Mental Health, assisted living, self-reporting.

\section{RESUMEN}

Este artículo pretende describir la experiencia en la aplicación del método de investigación de Heidegger, en particular las entrevistas fenomenológicas con las personas con enfermedad mental dados de alta en las instituciones psiquiátricas en las que se encuentran actualmente los residentes de la terapéutica de Servicios Residenciales (SRTS). Se entrevistaron a nueve residentes de la SRT en Piauí. Se repitió esta fase varias veces y los 
resultados fueron sorprendentes dado que incidió en la estrategia de acercamiento a los sujetos, el escenario de las entrevistas y en el nivel de agitación de los sujetos. Esta experiencia me permitió identificar lo que es necesario e importante para establecer empatía con los sujetos, no existe una fórmula para la realización de la entrevista, pero es el investigador el que debe identificar la mejor estrategia para la selección de los informantes. En conclusión, la empatía experimentada por el entrevistador al obtener los informes de los sujetos residentes mediante la entrevista fenomenológica resultó crucial para descubrir el significado de las vivencias de la vida cotidiana de estos sujetos en estas instituciones.

Palabras clave: salud mental, vida asistida, auto-informes.

\section{RESUMO}

Este artigo tem por objetivo descrever minha experiência na aplicação do método Heideggeriano de investigação, em particular a entrevista fenomenológica, com portadores de transtorno mental egressos de instituições psiquiátricas que atualmente são moradores de Serviços Residenciais Terapêuticos (SRTs). Foram entrevistados nove moradores de SRTs no Piauí. No caminhar dessa etapa vários momentos foram marcantes como: a estratégia de aproximação com os depoentes, o local das entrevistas e o próprio relato emocionante dos sujeitos. Essa experiência possibilitou-me identificar que é necessário e importante o estabelecimento da empatia com os sujeitos da pesquisa, que não existe formula para a condução da entrevista, mas cabe ao pesquisador identificar a melhor estratégia para a obtenção dos relatos. Assim é que a relação empática vivenciada por mim na obtenção dos relatos dos moradores depoentes em sua essência por meio da entrevista fenomenológica foi fundamental para se desvelar o sentido do vivido dos sujeitos no cotidiano desses dispositivos.

Palavras-chave: Saúde Mental, Moradias assistidas, Auto-relato.

\section{INTRODUÇÃO}

O portador de transtorno mental desde a idade média sofre exclusão social. Nesta época esse sujeito era tido como algo que profanava os preceitos da igreja católica, por agir de forma diferente aos preceitos difundidos por tal religião. Com o passar dos tempos, no período da renascença foi tido como pessoa improdutiva já que não servia para as atividades capitalistas de então. Surgem nesta época os hospitais gerais para 'varrer' a carga insana das cidades, silenciando assim a loucura (Silva; Fonseca, 2003. Foucault, 2003).

À época da revolução francesa, o 'louco', começa a ser 'tratado' em locais próprios, os hospitais psiquiátricos. Agora a ênfase seria dada a doença mental e esta seria tratada e não mais silenciada. Para tal seria necessário, segundo o criador destas instituições, Philippe Pinel, um tratamento moral e disciplinar para que esse sujeito voltasse a racionalidade (Basaglia, 2005).

Com o passar do tempo esse tratamento moral e disciplinar ganhou outros significados e condutas. Os portadores de transtorno mental além de serem excluídos socialmente receberiam tratamento desumano e marcado pelo sofrimento físico. Sob a lógica pineliana é difundido o pensamento de que as pessoas com problemas mentais deveriam ser encarceradas, retiradas do convívio 'normal' da sociedade e tratadas sob as mais variadas formas de coerção e privações. Essa lógica manicomial herdada desde a época de Pinel ainda hoje é 
vivida em nossa sociedade (Amarante, 2007)

Essa lógica começou a ser combatida, no Brasil, pela atual reforma psiquiátrica iniciada desde a década de 70. Porém com todos os avanços nessa área, culturalmente a lógica asilar ainda se faz hegemônica e esse sujeito ainda sofre sob o estigma social e consequentemente com a exclusão das pessoas que vivem ao seu redor.

Nesse contexto trabalhar com sujeitos portadores de transtorno mental é uma experiência complexa e muito delicada, uma vez que além de precisar ter uma sensibilidade muito grande para se poder compreender e assistir esses sujeitos, é necessário se abster de todos os preconceitos advindos ao longo do tempo para com essas pessoas. Elas precisam ser inseridas novamente em sociedade e a elas serem dados todos os direitos que lhes foram tirados ao longo dos tempos.

O presente trabalho trata da experiência vivenciada com sujeitos portadores de transtorno mental moradores de Serviços Residenciais Terapêuticos (SRTs) no Piauí. Esses sujeitos são pacientes egressos de longos períodos de internação em hospital psiquiátrico que estão estáveis em relação a sua patologia, porém não possuem suporte social e nem familiar para se manterem fora de instituições asilares.

Tais sujeitos são assistidos pelo governo federal em parceria com o estado, os quais destinam locais para eles viverem e serem novamente reinseridos na sociedade. Esses locais são moradias localizadas na comunidade com o objetivo de levar novamente a experiência do morar, do habitar e do compartilhar com as pessoas as experiências múltiplas de convívio social.

Wachs et al (2010) afirmam que os usuários de SRTs ao circularem pela cidade, ao se relacionarem com pessoas na sociedade, ao se apropriarem de lugares antes não habitados que produzam sentido para suas vidas, ao realizarem escolhas a partir de seus desejos e ao viverem novos processos de subjetivação, potencializam os processos de desinstitucionalização da loucura, objetivo tão almejado pela atual reforma psiquiátrica brasileira.

Diante do exposto o interesse em trabalhar com portadores de transtorno mental com quadro estável residentes de SRTs foi despertado à medida que percebeu-se a necessidade de dar voz à subjetividade desses sujeitos no tocante a vida nesses dispositivos pondo em evidência a melhoria de vida e a mudança da antiga vida marcada por sofrimento em hospitais psiquiátricos para uma vida de novas possibilidades na cidade.

Assim, o ingressar no mestrado em enfermagem pela Universidade Federal do Piauí, vislumbrando a possibilidade de pesquisar o presente tema, optou-se por buscar conhecer o vivido desses sujeitos enquanto principais atores sociais que vivenciam o fenômeno como ele é em sua essência. Como guia de investigação escolhi o método fenomenológico de Martin Heidegger, por ser adequado ao objeto do meu estudo: o vivido do ser-morador no cotidiano dos Serviços Residenciais Terapêuticos, e, por permitir desvelar o objeto como um fenômeno que parte da subjetividade e da experiência vivida, que só pode ser compreendido no sujeito que a vivencia.

A fenomenologia propõe um retorno aos fenômenos sendo estes definidos como aquilo que aparece a consciência como objeto intencional, há uma busca as essências captadas por uma visão que se encontra presente na experiência vivida. É uma possibilidade de olhar as coisas como elas se manifestam para descrevê-las com rigor, pois, através da descrição rigorosa é que se pode chegar à essência do fenômeno. Mostra e explicita o ser nele mesmo e se 


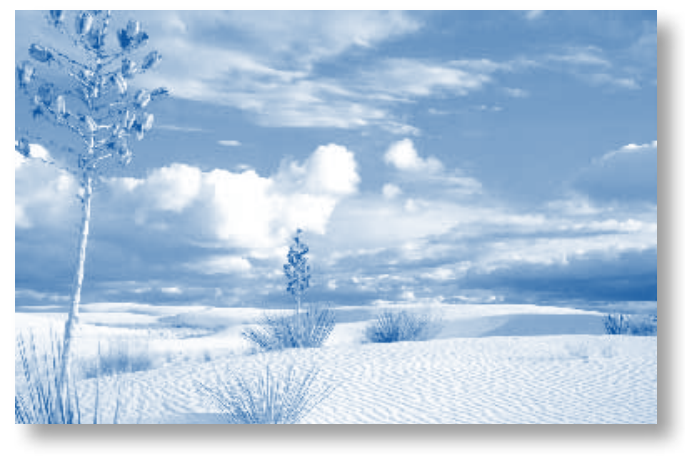

preocupa com a essência do vivido (Capalgo, 2008).

A fenomenologia possibilita um retorno às coisas nelas mesmas, conhecer o fenômeno como este se mostra a consciência. Através da linguagem possibilita desvelar o cotidiano do mundo do ser pesquisado, tornando realidade aquilo que faz sentido para esse ser (Monteiro et al, 2008).

$\mathrm{Na}$ obtenção da descrição do vivido do ser-morador no cotidiano dos SRTs utilizei a entrevista fenomenológica como recurso metodológico. Esta é uma etapa importante do método fenomenológico proposto pelo filósofo alemão Martin Heidegger. Este tipo de entrevista permite esclarecer o objeto como um fenômeno que parte da subjetividade e da experiência vivida que geralmente escapa à observação objetiva. Propõe-se a dar respostas quando se quer analisar um fenômeno e seus significados atribuídos pelos sujeitos que o vivem ou o experienciam (Monteiro, 2005).

$\mathrm{O}$ método fenomenológico Heideggeriano de investigação se apresenta em quatro momentos. A entrevista fenomenológica faz parte do primeiro momento do método. Neste o filósofo traz que é necessário se aduzir o sujeito através de questionamento e para isso uma relação de empatia deve ser estabelecida. $O$ pesquisador pergunta ao sujeito, durante a entrevista, e ele responde descrevendo o vivido, o percebido, a experiência (Monteiro,
2005). Essa descrição se faz pela linguagem, que se manifesta pela escrita, pela fala, pelos gestos ou mesmo pelo silêncio. Para que haja compreensão é necessária escuta atenta daquilo que se fala (Heidegger, 2009).

O segundo momento é de alerta, no qual o pesquisador deve realizar uma suspensão de juízo de valor diante do fenômeno descrito pelo interrogado. Husserl denominou esta etapa de epoché, ou seja, é a suspensão de toda carga de crenças, significados, percepções que o pesquisador pode deter sobre o fenômeno (Martins; Bicudo, 2006). Segundo o método em questão não se deve aplicar nenhuma idéia do pesquisador por mais evidente que seja.

O terceiro momento em Heidegger é a compreensão vaga e mediana, onde os significados são atribuídos pelos sujeitos sobre determinado fenômeno. E o ultimo momento é a interpretação ou hermenêutica onde o sentido é desvelado do ser pesquisado a partir das estruturas fundamentais desse ser.

Com base no primeiro momento do método em Heidegger, o qual foi considerado de extrema importância para aproximação entre sujeito e pesquisador, bem como de fundamental relevância para os resultados da pesquisa é que se fez um relato sobre como se deu essa interação. Assim este artigo tem como objetivo descrever minha experiência na aplicação do método Heideggeriano de investigação, em particular a entrevista fenomenológica, com egressos de instituições psiquiátricas que atualmente são moradores de Serviços Residenciais Terapêuticos (SRTs). A entrevista buscou o sentido do vivido desses sujeitos nesses dispositivos.

\section{APROXIMAÇÃO DOS SUJEITOS E OB- TENÇÃO DOS RELATOS}

Foram entrevistados nove moradores em dois municípios do Piauí, Teresina e União. 
Antes de realizar a entrevista foram organizados encontros com os sujeitos para se estabelecer a empatia entre pesquisador e pesquisado, para que o modo genuíno de acesso ao sujeito fosse conseguido.

É importante salientar que a pesquisa de mestrado da Universidade Federal do Piauí da qual esse relato se originou foi submetida à apreciação e aprovação pelo comitê de ética e pesquisa (CEP) da referida universidade, aprovada sob o numero CAAE-0252.0.045.000-10. Foram obedecidos todos os critérios da resolução 196/96, que regulamenta a pesquisa envolvendo seres humanos.

No caminhar por essa etapa vários momentos foram marcantes e outros difíceis de conduzir. As dificuldades resultaram de dois elementos principais: Pirmeiro por que o método Heideggeriano de investigação possui um rigor particular e deve ser seguido de forma minuciosa se obedecendo todos os pressupostos e segundo por que mesmo sendo estudiosa da saúde mental descobri que ainda tinha alguns preconceitos com relação aos sujeitos entrevistados.

Inicialmente na fase de aproximação me deparei com algumas surpresas. Em meu imaginário, fruto da lógica incapacitante dada ao sujeito portador de transtorno mental, difundida pela lógica manicomial que permeia nossa sociedade, este não iria responder ao rigor metódico desse tipo de pesquisa e iria ser difícil o acesso a esse sujeito.

Surpreendi-me com a recepção calorosa e lúcida dos entrevistados. Foram necessários alguns encontros e conversas antes da entrevista propriamente dita com os moradores para que a empatia entre pesquisador e pesquisado fosse estabelecida. A relação empática foi primordial para que o ser-sujeito se revelasse em sua essência.
As conversas foram muito enriquecedoras e nesses encontros não só expliquei aos moradores sobre aspectos relevantes da pesquisa como também pude perceber como esses sujeitos possuem modos de vida particulares como qualquer pessoa dita "normal", são pessoas comuns que vivem um cotidiano diferenciado somente pelo fato de sofrerem de um transtorno psíquico e infelizmente por causa disso serem estigmatizados pelos que vivem ao seu redor.

Após os encontros iniciais realizados pude superar preconceitos existentes em meu imaginário com relação ao portador de transtorno mental e também pude perceber como esses sujeitos sofrem psiquicamente com o tratamento dado a eles pela sociedade.

As entrevistas aconteceram em local reservado escolhido pelo entrevistado para que o mesmo se mostrasse em sua essência. Aqui cabe ressaltar que todos os moradores dos SRTs pesquisados se encontravam estáveis com relação a sua patologia no momento da entrevista.

Com relação ao local das entrevistas tive um pouco de dificuldade no início uma vez que o local deveria ser reservado e livre de acontecimentos que pudessem vir a interferir no relato espontâneo do sujeito. Nos SRTs pesquisados além dos nove entrevistados ainda residiam outros moradores com algumas dificuldades de linguagem ou de comunicação. Estes no início se mostraram um pouco insatisfeitos com a impossibilidade de serem entrevistados, e de certa forma acabavam atrapalhando as tentativas de entrevistas.

Como havia essa intervenção, as entrevistas eram suspensas e agendadas para outro dia. Foram necessárias algumas conversas com os moradores não entrevistados e com o passar do dias o problema foi resolvido. Os relatos foram obtidos individualmente em locais onde $o$ entrevistado se sentisse à vontade para relatar 
a essência do seu vivido nos SRTs.

$\mathrm{O}$ fato mais marcante da entrevista foi $\mathrm{o}$ próprio relato emocionante dos sujeitos sobre a vida durante a internação em instituições psiquiátricas e a nova vida em SRTs. Não só a fala era gravada em dispositivo digital como também eram realizadas anotações em um diário de campo de outras formas de discurso observadas durante as entrevistas como a não verbal, e do silêncio, o que contribuiu posteriormente para interpretação dos resultados.

Em muitos momentos os sujeitos se emocionavam quando relatavam sobre as mudanças ocorridas em suas vidas como se mostravam entristecidos em suas feições quando falavam do tratamento recebido em instituições psiquiátricas e preconceito e estigma da sociedade por exemplo. Por inúmeras vezes, nos momentos dos depoimentos emocionava-me e comovia-me com suas falas, várias vezes sentei e chorei junto com os entrevistados

Ao final das entrevistas pude perceber o quão rico é o método fenomenológico e como o ser se faz compreender a partir da entrevista. Dessa forma a entrevista fenomenológica foi determinante para aproximação do modo de ex-sistir desses sujeitos no seu cotidiano de vida, desvelando o que vêm ao encontro de acordo com o seu modo de ser-no-mundo.

\section{CONSIDERAÇÕES FINAIS}

Esse meu caminhar pelo método Heideggeriano de investigação, em especial a entrevista fenomenológica possibilitou-me a identificação de que é necessária é necessário e importante o estabelecimento da empatia com os sujeitos da pesquisa e que não existe fórmula para a condução da entrevista, mas cabe ao pesquisador a melhor estratégia para a obtenção dos relatos.

A relação empática vivenciada por mim na obtenção dos relatos dos moradores depoentes em sua essência por meio da entrevista fenomenológica foi fundamental para se desvelar o sentido do vivido dos sujeitos no cotidiano desses dos SRTs.

\section{REFERÊNCIAS}

- Amarante P. (2007) Saúde mental e atenção psicossocial. Rio de Janeiro (Brasil): Fiocruz.

- Basaglia F. (2005) O circuito do controle: do manicômio à descentralização psiquiátrica. In: Amarante $\mathrm{P}$ (organizador). Escritos selecionados em saúde mental e reforma psiquiátrica. Rio de janeiro (Brasil): Garamond.

- Capalgo C. (2008) Fenomenologia e ciências humanas. Aparecida, SP (Brasil): Idéias \& Letras.

- Foucault M. (2003) A História da Loucura. São Paulo (Brasil): Ed. Perspectiva.

- Heidegger M. (2009) Ser e Tempo. 4. ed. Petrópolis: Vozes.

- Monteiro CFS. (2005) Marcas no corpo e na alma de mulheres que vivenciam a violência conjugal: uma compreensão pela enfermagem [tese].Rio de Janeiro (RJ): Escola de Enfermagem Anna Nery, Universidade Federal do Rio de Janeiro.

- Monteiro CFS et al. (2008) Vivências maternas na realidade de ter um filho autista: uma compreensão pela enfermagem. Rev Bras Enferm, 61(3): 330-335.

- Martins J, Bicudo MAV. (2006). A pesquisa qualitativa em psicologia. São Paulo (Brasil): Centauro.

- Wachs F et al . (2010) Processos de subjetivação e territórios de vida: o trabalho de transição do hospital psiquiátrico para serviços residenciais terapêuticos. Physis, 20(3): 895-912. 